\title{
MEDICINAL LEECHES AND THE MICROSURGEON: A FOUR-YEAR STUDY, CLINICAL SERIES AND RISK BENEFIT REVIEW
}

\author{
IAIN S. WHITAKER, B.A (Hons)., M.A., M.B.B Chir., M.R.C.S., Ph.D., F.R.C.S (Plast)., ${ }^{1 *}$ \\ IAN C. JOSTY, B.Sc., F.R.C.S., F.R.C.S (Plast)., ${ }^{1}$ SIMON HAWKINS, M.B.Ch.B., M.R.C.S., ${ }^{1}$ ERNEST AZZOPARDI, M.Sc., M.R.C.S., M.D., ${ }^{1}$ \\ NAGHMEH NADERI, M.D., M.R.C.S., ${ }^{1}$ JOERG GRAF, Ph.D., ${ }^{2}$ LISA DAMARIS, B.Pharm (Hons)., M.R.Pharm.S., Dip., ${ }^{1}$ \\ WILLIAM C. LINEAWEAVER, M.D., F.A.C.S., ${ }^{3}$ and MOSHE KON, M.D., Ph.D. ${ }^{4}$
}

\begin{abstract}
Background: There are case reports and small series in the literature relating to the use of medicinal leeches by plastic surgeons; however, larger series from individual units are rare. The aim of this article is to present a comprehensive 4-year case series of the use of medicinal leeches, discuss the current evidence regarding indications, risks, and benefits and highlight the recent updates regarding leech speciation. Methods: Patients prescribed leeches in a 4-year period (July 2004-2008) were collated from hospital pharmacy records $(N=$ 35). The number of leeches used, demographic, clinical, and microbiological details were retrospectively analyzed. Results: Thirty-five patients were treated with leeches. The age range was 2 to 98 years (mean $=49.3$ ). Leeches were most commonly used for venous congestion in pedicled flaps and replantations. Blood transfusions were necessary in 12 cases $(34 \%)$ [mean $=2.8$ units, range $2-5$ units]. Our infection rate was $20 \%$ (7/35) including five infections with Aeromonas spp. (14.2\%). The proportion of patients becoming infected after leech therapy was significantly greater in the group of patients that did not receive prophylactic antibiotic treatment (Fisher's Exact test $P=0.0005)$. In total, 14 cases (40\%) were salvaged in entirety, in 7 cases $80 \%$ or more, in 2 cases 50 to $79 \%$, and in 1 case less than $50 \%$ of the tissues were salvaged. In 11 cases $(31 \%)$, the tissues were totally lost. Conclusion: Our study highlights both the benefits and the risks to patients in selected clinical situations and also the potential risks. The routine use of antibiotic prophylaxis is supported. In view of the emerging evidence that Hirudo verbana are now used as standard leech therapy, and the primary pathogen is Aeromonas veronii, until a large prospective multicenter study is published, large series of patients treated with leeches should be reported. (0)2011 Wiley-Liss, Inc. Microsurgery 31:281-287, 2011.
\end{abstract}

Medicinal leech therapy is currently drawing both highprofile public and scientific attention as novel indications are explored for this ancient treatment. ${ }^{1}$ The early success of leech therapy in plastic and reconstructive surgery ${ }^{2}$ and, more recently, its effectiveness in treating chronic pain syndromes associated with degenerative diseases ${ }^{3}$ have helped leech therapy gain acceptance in modern clinical medicine. ${ }^{4}$ The Food and Drug Administration of the United States only recently approved the use of the leech as a medical device. ${ }^{5}$ The medicinal leech, Hirudo medicinalis, is protected internationally by its listing on appendix II of the Convention on International Trade in Endangered Species of Wild Fauna and Flora and in the United Kingdom specifically under Schedule 5 of the Wildlife and Countryside Act 1981. Most commercial suppliers still market medicinal leeches as $H$. medicinalis; however, a recent study revealed that many leeches sold

\footnotetext{
${ }^{1}$ Welsh Centre for Burns and Plastic Surgery, Morriston Hospital, Swansea, UK 2Department of Molecular and Cell Biology, University of Connecticut, Storrs, CT ${ }^{3} \mathrm{Dr}$ William C Lineaweaver MD FACS, Rankin Plastic Surgery Center, Brandon, MS

${ }^{4}$ Professor Moshe Kon MD PhD, Professor and Head of Department, Plastic, Reconstructive and Hand Surgery, Utrecht Medical Centre, Utrecht, the Netherlands

*Correspondence to: lain Stuart Whitaker, B.A (Hons)., M.A., M.B.B., M.R.C.S., Ph.D., F.R.C.S., Welsh Centre for Burns and Plastic Surgery, Department of Plastic, Reconstructive and Burns Surgery, Morriston Hospital, Swansea, SA66 NL, UK. E-mail: iainwhitaker@fastmail.fm

Received 3 July 2010; Revision accepted 16 October 2010; Accepted 19 October 2010

Published online 25 April 2011 in Wiley Online Library (wileyonlinelibrary.com). DOI 10.1002/micr.20860
}

were genetically distinct from $H$. medicinalis and identified as $H$. verbana. ${ }^{6}$ The predominance of $H$. verbana is likely due to overharvesting of $H$. medicinalis in the 19th century at the peak of their popularity and the loss of wetlands.

These two different types of leech can be distinguished based on differences in color patterns on their dorsal and ventral body surfaces. Some authors are encouraging the use of "DNA Barcodes" such as cytochrome oxidase I (COI) gene sequences to reveal genetic variations in different types of leeches ${ }^{7}$ as there can be a wide variation in physical appearance. Clarification of these differences with regard to medical or microbiological differences will continue over the coming years.

Early attempts to characterize the digestive tract microbiota were limited by their purely culture-based approach. It is now widely recognized that around $99 \%$ of microbes are presently unculturable. ${ }^{8}$ Recent studies have indicated that differences exist in the microbial communities of Hirudo verbana and Hirudo orientalis., ${ }^{9,10}$ The microbial community of Hirudo medicinalis is currently under investigation with similar advanced techniques. Current studies are ongoing to elucidate the differences between the anticoagulant profiles of different Hirudo species. ${ }^{11}$

The use of leeches by plastic surgeons to aid salvage of compromised microvascular free-tissue transfers, ${ }^{12,13}$ venously congested digits, ${ }^{14-16}$ nipples, ${ }^{17}$ ears,${ }^{18}$ lips, ${ }^{19}$ nasal tips, ${ }^{20}$ and even the penis ${ }^{21}$ has been reported. There are several case reports and small series in the 


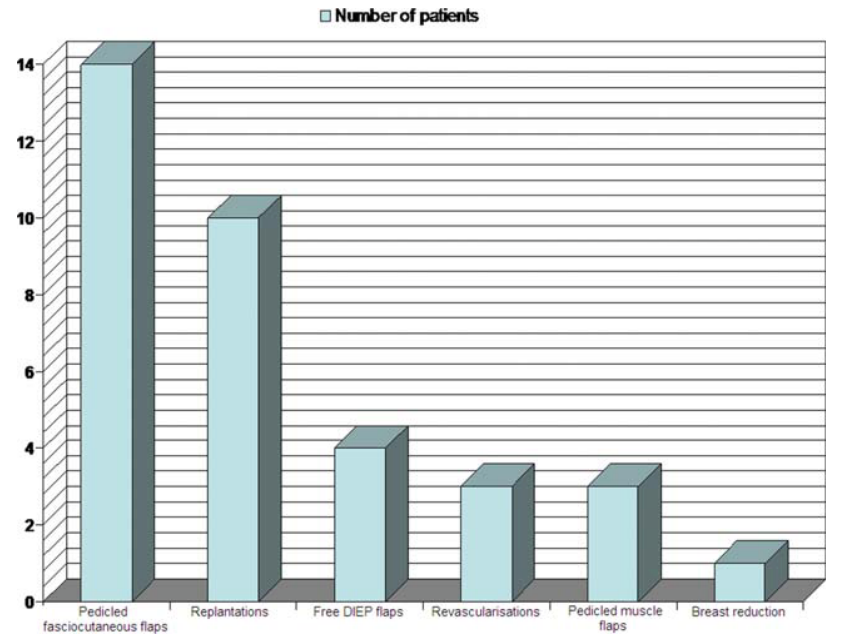

Figure 1. Indications for treatment with leeches (July 2004-July 2008). DIEP=Deep Inferior Epigastric artery Perforator. [Color figure can be viewed in the online issue, which is available at wileyonlinelibrary.com.]

literature relating to the use of medicinal leeches in plastic surgery; however, larger series from individual units with clinical analysis are rare. ${ }^{22}$ In this article, we present a comprehensive 4-year case series of the use of medicinal leeches in a plastic surgery centre and discuss the current thinking with regard to indications, risks, and benefits.

\section{METHODS}

The hospital numbers and dates of birth of all patients prescribed leeches in the 4-year period (July 2004-July 2008) were collated from hospital pharmacy records $(N=35)$. Using this information, the hospital notes were retrieved and both demographic and clinical details were retrospectively analyzed. Using the patients' hospital numbers, the medical notes and microbiology database were accessed, and all transfusion requirements, swab results, and antibiotic treatments for the "leech episode" were documented. The total number of leeches used over the same 4-year period (July 2004-July 2008) was also collated from pharmacy records. From this data, the total financial cost per year was calculated.

The proportion of patients becoming infected as a result of leech therapy was compared between the group of patients that did not receive prophylactic antibiotic treatment and the group that did. A two-sided $P$ value was calculated using Fisher's test with GraphPad prism software.

\section{RESULTS}

Our study group included 35 patients treated with leeches between July 2004 and July 2008. The age range was 2 to 98 years $($ mean $=49.3)$. Seventeen patients $(49 \%)$ were females, and the remaining $18(51 \%)$ were male. There was a wide range of indications for treatment (See Fig. 1), with leeches most commonly used for venous congestion in cutaneous pedicled flaps and replantations. Treatment with leeches was started within 48 hours in 32/35 cases (See Fig. 2a) and only once was it started on day 4 . None of the patients included in the study underwent surgical re-exploration for venous congestion and, no venous supercharging procedures were performed before leech therapy. The average length of leech treatment was 5.6 days (range 1-13 days) (See Fig. 2b). Blood transfusions were necessary in 12 cases $(34 \%)$ [mean $=2.8$, range $2-5$ units] (See Fig. 2 c). In our series, we encountered an infection rate of $20 \%$ (7/ 35) including five infections with Aeromonas hydrophila $(14.2 \%)$. Of note, all five isolates of Aeromonas were sensitive to ciprofloxacin. Antibiotic prophylaxis was highly variable depending on the consultant in charge. Only 16 of 35 patients $(46 \%)$ received antibiotic prophylaxis (4 co-amoxiclav, 6 ciprofloxacin, 3 co-amoxiclav and ciprofloxacin, 1 metronidazole and co-amoxiclav, 1 cefuroxime, and 1 flucloxacillin and phenoxymethylpenicillin). The proportion of patients becoming infected after leech therapy was significantly greater in the group of patients that did not receive a prophylactic antibiotic treatment compared with the group of patients who did receive antibiotic prophylaxis (26\% vs. $12.5 \%$, Fisher's exact test $P=0.0005$ ). Of the seven infected cases, one case of Pseudomonas spp. infection was successfully treated with ciprofloxacin resulting in $80 \%$ salvage, one infection with methicillin-resistant Staphylococcus aureus resulted in $100 \%$ flap loss, two cases of infection due to Aeromonas hydrophila were successfully treated with ciprofloxacin resulting in a $100 \%$ salvage rate, one infection with Aeromonas hydrophila was treated with augmentin resulting in 90\% salvage, and two cases of Aeromonas infection contributed to complete flap loss. Our infection rate with Aeromonas spp. was $14.2 \%$ (5/35), with a salvage rate of $60 \%(3 / 5)$. The identification of the wound isolates was performed in a clinical diagnostic laboratory. Because of the difficulties of identifying Aeromonads and the inaccuracies of commercial kits to identify especially environmental isolates, these identifications may not be accurate but reflect the information given to the treating physicians.

In total following leech therapy, 14 cases (40\%) were salvaged in entirety; in 7 cases, $80 \%$ or more of the tissue was salvaged; in 2 cases, 50 to $79 \%$ of the flap was salvaged; in one case, more than $50 \%$ of the flap was lost, and, in 11 cases $(31 \%)$, the tissues were totally lost (See Fig. 2d).

In the management of congested replanted digits, we salvaged 7 of 10 cases $(70 \%)$ in our series (See Table 1). Additionally, we were able to salvage $>90 \%$ of the flap surface area in $77 \%$ of our cutaneous pedicled flaps, which were exhibiting signs of venous congestion postoperatively (See Table 1). In free-tissue transfers, there was a $100 \%$ 
a

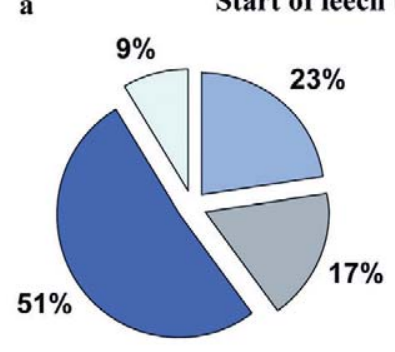

c

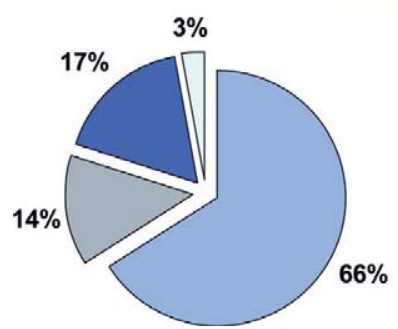

b

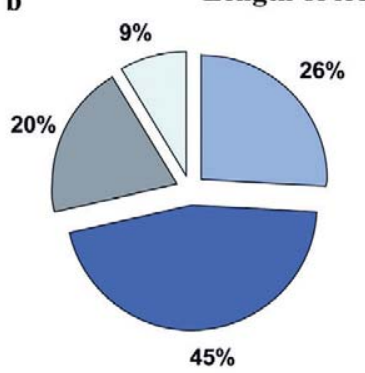

Length of leech therapy

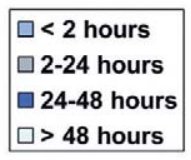

$45 \%$

d

Outcomes following leech therapy

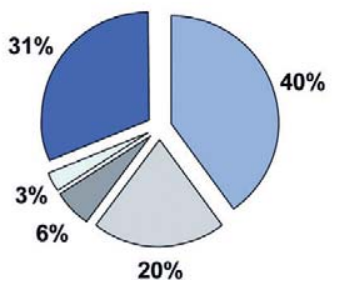

$\square$ 1-3 days

$\square$ 4-6 days

$\square$ 7-10 days

$\square>10$ days

Figure 2. Data regarding leech therapy from July 2004-July 2008). a: Start of leech therapy, b: length of leech therapy, c: blood transfusion requirements, and d: outcomes following leech therapy. [Color figure can be viewed in the online issue, which is available at wileyonlinelibrary.com.]

Table 1. Leech Therapy for Venous Congestion Following Reconstructive Surgery in 35 Patients (July 2004-July 2008)

\begin{tabular}{|c|c|c|c|}
\hline & & $\begin{array}{l}\text { Leech application with } \\
\text { prophylactic antibiotics (cases) }\end{array}$ & $\begin{array}{l}\text { Leech application without } \\
\text { prophylactic antibiotics (cases) }\end{array}$ \\
\hline \multirow[t]{5}{*}{ Clinical problems } & Traumatic complete or partial amputation & 5 & 6 \\
\hline & Open fracture and wound breakdown & 3 & - \\
\hline & Tumor resection & 6 & 6 \\
\hline & Degloving or crush injury & - & 6 \\
\hline & Other & 2 & 1 \\
\hline \multirow{3}{*}{$\begin{array}{l}\text { Reconstructive } \\
\text { solution }\end{array}$} & Replantation and revascularization & 5 & 9 \\
\hline & Pedicled flap & 9 & 8 \\
\hline & Free flap & 1 & 3 \\
\hline \multirow{5}{*}{$\begin{array}{l}\text { Clinical } \\
\text { infection }\end{array}$} & Anaerobes and/or Aeromonas spp. and/or MRSA & 1 & 2 \\
\hline & Aeromonas hydroph, Corynebacterium spp & 1 & - \\
\hline & Pseudomonas spp & - & 1 \\
\hline & Staphylococcus aureus and Aeromonas spp. & - & 1 \\
\hline & $\begin{array}{l}\text { Enterococcus fecalis, Aeromonas spp., } \\
\text { Morganella, morgagni, streptococcus }\end{array}$ & - & 1 \\
\hline \multirow[t]{5}{*}{ Flap survival } & $100 \%$ & 4 & 10 \\
\hline & $>80 \%$ & 6 & 1 \\
\hline & $50-79 \%$ & 2 & - \\
\hline & $<50 \%$ & - & 1 \\
\hline & $0 \%$ & 4 & 7 \\
\hline
\end{tabular}

Patient factors and demographics, antibiotic prophylaxis, prevalence of infection, microbiology results, and salvage rates are listed.

loss despite the use of leeches in all four cases of venous congestion (See Table 1).

The number of leeches to be used depends on the volume of the congested tissue. On a digital replant, for example, two leeches are sufficient, whereas larger pedicled flaps may need as many as five or six leeches. Over the period from 2004 to 2008, there was a gradual increasing trend in the use of leeches from 2004 to 2006, peaking at 858 leeches in 2006 with a return to 330 and
457 leeches for 2007 and 2008, respectively. Over this time period, the cost of leeches was stable at $£ 11.54$ per leech giving a collective peak cost of $£ 9221$ in 2006 .

\section{DISCUSSION}

\section{Indications}

Leeches are widely used by plastic, maxillofacial, and other reconstructive surgeons to aid salvage of a variety of 
venously congested tissues. The two most common indications for leech use in this series included cutaneous pedicled flaps, first described by Derganc and Zdravic ${ }^{2}$; and replantations, which Foucher so clearly defined in $1981 .^{23}$ For these indications, with appropriate antibiotic prophylaxis, we believe leeches should always be considered in the absence of the relative contraindications outlined below.

Tamai, ${ }^{24}$ when reporting on his 20-year experience of over 290 replantations, stated that there was only a $17 \%$ salvage rate in replanted digits exhibiting venous congestion postoperatively. He never used leeches. Foucher et al., when using leeches routinely, recorded an overall salvage rate of 55-60 percent. $^{23}$ These figures are comparable to our figures (70\%) (See Table 1). The unsuccessful replants tended to be those with either a crush component to the initial soft tissue injury or degloving injuries. Although it is impossible to prove beyond doubt, in our clinical opinion, without the use of leeches, some of these replants would have failed.

The salvage rate of our pedicled cutaneous flaps (77\%) was comparable with the salvage rate of $70 \%$ described by Derganc and Zdravic ${ }^{2}$ in their seminal paper on the subject.

Although we believe their clinical utility is beyond doubt, leeches are not the answer for all postoperative problems. This has proven to be the case mainly in the treatment of congested free-tissue transfers. Our experience in using leeches on free Deep Inferior Epigastric artery Perforator (DIEP) flaps was poor. This further reinforces the notion that in free flaps developing a problem with venous drainage, the treatment of choice should be re-exploration of the anastomosis if at all possible. In our free flap cases, this was not performed due to a combination of both patient and technical factors. Recent experimental evidence suggests that venous supercharging by using additional routes of venous drainage can have a statistically significant benefit with a correlation shown between the number of venous outflow routes and survival of free flaps and reduction in the incidence of venous congestion. ${ }^{25,26}$ A recent retrospective review of 564 consecutive DIEP flaps at a single institution showed that the use of a secondary vein in the drainage of a DIEP flap can significantly reduce the incidence of venous congestion without any significant effect on the incidence of complete flap failure and overall takebacks. ${ }^{27}$ They also demonstrated that the use of a secondary vein does not significantly increase operative times. Although initial results are promising, further large clinical studies are needed to demonstrate the benefits of venous supercharging procedures in free-tissue transfers.

\section{Relative Contraindications}

These include arterial insufficiency, immunosuppression, patients with a bleeding diathesis, Jehovah's witnesses, ${ }^{28}$ those who have previously exhibited allergy to leeches or their foreign proteins, ${ }^{29}$ and individuals with a psychological aversion to the annelid's use. ${ }^{22}$ Those with diabetes and smokers in particular should be counselled on the theoretical increased risks of infection and treatment failure.

\section{Start of Treatment}

Leech therapy was started in the first 48 hours $91 \%$ of the time. There was no relationship between the commencement of leech therapy and outcome. It has been postulated that leech therapy should be commenced at the earliest sign of outflow compromise, ${ }^{22}$ although to our knowledge there has been no definitive proof that a reasonable delay in application affects outcome.

\section{Length of Treatment}

In our series, the average length of leech treatment was 5.6 days (range 1-13 days). (See Fig. 2b) It is evident that when leeches are the only source of venous outflow leech treatment should be continued until inosculation occurs. On the basis of experimental animal models, this process needs 3 to 5 days; however, limited clinical data suggests that 6 to 10 days are necessary. ${ }^{30}$ A previous meta-analysis has quoted the average leech therapy to be 4.2 days. $^{22}$

\section{Number and Timing of Leech Application}

In general, the volume of leeches used per plastic surgery unit per unit time, and the number of leeches used per patient reflects enormous diversity of opinion and practice, and there is little in the literature studying this. Over the period from 2004 to 2008, the use of leeches peaked at 858 leeches in 2006 with a peak cost of $£ 9221$ per financial year. It is unclear whether a reduction in the number of leeches used would reduce the cost, infection rates, and transfusion requirements while maintaining clinical outcomes. There is little doubt that the cost of "leeching" is likely to be cheaper than additional revisional surgery necessary in the absence of leeching.

In our experience, leeches should be applied every 6 hours, as evidence from the literature shows that over $90 \%$ of passive bleeding occurs within 5 hours. This 6 hourly application time allows for feeding and passive bleeding. A commonly asked question is how many leeches to use and how often. There is no clarity in the literature regarding this question, and a wide variety of regimes have been used. It is impossible to assess accurately the number of leeches used per patient and the timing of application, as this was not stringently logged on a patient by patient basis. Greater numbers of leeches are likely to require high-dependency unit admission, regular hemoglobin checks and blood transfusions. 


\section{Transfusion Requirements}

Persistent and prolonged bleeding after the removal of the leech has long been considered a complication. In 1819, White reported that a 2-year-old girl had died due to excessive blood loss induced by a single leech. ${ }^{31}$ Although adverse events associated with blood transfusions are improving, they still cause morbidity and mortality in both adult ${ }^{32}$ and pediatric populations. ${ }^{33}$

In our experience, blood transfusions were necessary in 12 cases $(34 \%)$ [mean $=2.8$ units, range 2-5 units]. All four of the DIEP flap patients required blood transfusions and none of the replantations. Clearly, the need for transfusion will depend on patients' comorbidities and the nature of the operative intervention; however, the use of leeches certainly potentiates bleeding risk. As stated by Lineweaver et al., ${ }^{16}$ the application of leeches to replants is a different situation to that of free-tissue transfers. Restoring circulation in these tissues by exsanguinations is likely to result in a prohibitive amount of blood loss. To support this argument, $100 \%$ transfusion requirements have been reported by Chepeha et al. ${ }^{34}$ in a small series of head and neck free-tissue transfers salvaged with leeches and intensively monitored in Michigan. These patients required an average of 13 units (range 5-28 units). Transfusion requirements of up to 78 units have been reported in some units. ${ }^{35}$ In his meta-analysis, Chaplain suggested a $66 \%$ requirement for blood transfusion (mean $=4.4$ units). Problematic bleeding in the majority of cases can be well controlled with direct pressure and topical thrombin. It is sensible to keep a daily check on the hemoglobin during leech therapy, particularly in young children. ${ }^{36}$ Previous studies have shown that any combination of anticoagulant therapy in addition to the use of leeches leads to a substantial increase in the need for blood transfusion. ${ }^{37}$

\section{Infection}

The plastic surgery community has been aware of the infection risk associated with leech application since it was first reported in the British Medical Journal by Dickson, ${ }^{38}$ and, then 3 years later, when it was discussed by Whitlock in the British Journal of Plastic Surgery. ${ }^{39}$ Since then, a high incidence of infection during and after application of medicinal leeches has been widely reported despite external decontamination. The exact incidence of leech-associated infection associated with postoperative use is difficult to assess, with incidences ranging from $2.4 \%$ to $36.2 \%$ being reported in the literature. ${ }^{39,40}$ Despite several publications advocating prophylactic antibiotics to combat leech-borne infections, ${ }^{16,41}$ many units either do not use antibiotic prophylaxis at all or continue to use less effective agents. ${ }^{36}$
The leech bite, created by three jaws, each containing 60 to 100 pairs of cutting teeth, forms a characteristic Y-shaped triradiate conformation $1 \mathrm{~mm}$ in diameter and up to $1.5 \mathrm{~mm}$ in depth. ${ }^{42}$

The combination of local tissue damage, along with contact between the oral and digestive tract flora, and the patient allows the potential for infection. Extensive studies have been carried out on the surface, mouth, and digestive-tract microbiota of leeches, ${ }^{8,41,43}$ which show Aeromonas spp. to be prominent in the resident flora. The venous congestion in plastic surgery patients leads to a localized area of immunocompromise that is more susceptible to infection. The most common clinical presentation is of cellulitis ${ }^{44}$ and, in severe cases, extensive tissue loss and septicemia has been reported. ${ }^{45}$ Aeromonas seems to have an affinity for muscle tissue, and is capable of producing extensive proteolytic enzymes leading to a picture resembling clostridial myonecrosis with gas production. ${ }^{46}$ The ability of Aeromonas to invade the walls of blood vessels with resultant vasculitis, thrombosis, and hemorrhagic necrosis is of most concern to microsurgeons.

Over the 4-year study period, there were seven cases of infection post leech therapy. Our infection rate with Aeromonas spp. was $14.2 \%(5 / 35)$, with a salvage rate of $60 \%(3 / 5)$ (See Table 1). This is a satisfactory salvage rate considering the meta-analysis by de Chalain et al. ${ }^{22}$ reporting on a clinical series of replants, free and pedicled flaps. His study reported a drop in the salvage rate of tissues from an expected $60-80 \%$ to $31.8 \%$ in infected tissues. Most authors in this analysis reported a complete loss of infected tissues. Aeromonas infections typically require treatment with aggressive debridement and antibiotic therapy, and this practice was followed in our series. Seminal microbiological studies by Lineweaver et al. ${ }^{41,47}$ show that in patients receiving prophylactic quinolones, there were significant decreases in leech enteric bacterial cultures.

In our clinical series, the proportion of patients becoming infected after leech therapy was significantly greater in the group of patients that did not receive a prophylactic antibiotic treatment (Fisher's exact test $P=$ 0.0005).

Despite the emerging evidence, high levels of resistance to first generation cephalosporins, penicillins (via $\beta$-lactamases), tetracyclines, and augmentin have been observed in studies, ${ }^{48}$ with fluoroquinoles seeming to be consistently active. ${ }^{49}$ Even new and widely used textbooks ${ }^{50}$ continue to advocate the use of potentially ineffective agents such as amoxicillin and clavulanic acid preparations (co-amoxiclav). Our experience and those of others suggest that prophylactic fluoroquinolones seem to be mandatory given the preponderance of infection. 


\section{CONCLUSION}

Despite the widespread use of leeches worldwide, we believe that there are insufficient prospective studies with large enough numbers to inform the microsurgical specialist on outcomes from leech usage and the risks and benefits for each indication. Our future research efforts will involve an interdisciplinary prospective multicenter study combining genetic clarification of leech types, hematological parameters, outcome analysis, and isolates from surgical wounds.

\section{REFERENCES}

1. Pilcher H. Medicinal leeches: Stuck on you. Nature 2004;432:10-11.

2. Derganc M, Zdravic F. Venous congestion of flaps treated by application of leeches. Br J Plast Surg 1960;13:187-192.

3. Michalsen A, Klotz S, Ludtke R, Moebus S, Spahn G, Dobos GJ. Effectiveness of leech therapy in osteoarthritis of the knee: A randomized, controlled trial. Ann Intern Med 2003;139:724-730.

4. Michalsen A, Ludtke R, Cesur O, Afra D, Musial F, Baecker M, Fink M, Dobos GJ. Effectiveness of leech therapy in women with symptomatic arthrosis of the first carpometacarpal joint: A randomized controlled trial. Pain 2008;137:452-459.

5. Rados C. Beyond bloodletting: FDA gives leeches a medical makeover. FDA Consum 2004;38:9.

6. Siddall ME, Trontelj P, Utevsky SY, Nkamany M, Macdonald KS. Diverse molecular data demonstrate that commercially available medicinal leeches are not Hirudo medicinalis. Proc Biol Sci 2007;274:1481-1487.

7. Bely AE, Weisblat DA. Lessons from leeches: A call for DNA barcoding in the lab. Evol Dev 2006;8:491-501.

8. Graf J, Kikuchi Y, Rio RV. Leeches and their microbiota: Naturally simple symbiosis models. Trends Microbiol 2006;14:365-371.

9. Laufer AS, Siddall ME, Graf J. Characterization of the digestivetract microbiota of Hirudo orientalis, a European medicinal leech. Appl Environ Microbiol 2008;74:6151-6154.

10. Worthen PL, Gode CJ, Graf J. Culture-independent characterization of the digestive-tract microbiota of the medicinal leech reveals a tripartite symbiosis. Appl Environ Microbiol 2006;72: $4775-4781$.

11. Baskova IP, Kostrjukova ES, Vlasova MA, Kharitonova OV, Levitskiy SA, Zavalova LL, Moshkovskii SA, Lazarev VN. Proteins and peptides of the salivary gland secretion of medicinal leeches Hirudo verbana, $\mathrm{H}$. medicinalis, and H. orientalis. Biochemistry 2008;73:315-320.

12. Batchelor AG, Davison P, Sully L. The salvage of congested skin flaps by the application of leeches. Br J Plast Surg 1984;37:358-360.

13. Connor NP, Conforti ML, Heisey DM, Vanderby R, Kunz D, Hartig GK. Augmented blood removal after medicinal leech feeding in congested tissue flaps. J Rehabil Res Dev 2002;39:505-512.

14. Brody GA, Maloney WJ, Hentz VR. Digit replantation applying the leech Hirudo medicinalis. Clin Orthop Relat Res 1989:133-137.

15. Durrant C, Townley WA, Ramkumar S, Khoo CT. Forgotten digital tourniquet: Salvage of an ischaemic finger by application of medicinal leeches. Ann R Coll Surg Engl 2006;88:462-464.

16. Lineaweaver WC, O'Hara M, Stridde B, Valauri FA, Buncke HJ. Clinical leech use in a microsurgical unit: The San Francisco experience. Blood Coagul Fibrinolysis 1991;2:189-192.

17. Gross MP, Apesos J. The use of leeches for treatment of venous congestion of the nipple following breast surgery. Aesthetic Plast Surg 1992;16:343-348.

18. de Chalain T, Jones G. Replantation of the avulsed pinna: 100 percent survival with a single arterial anastomosis and substitution of leeches for a venous anastomosis. Plast Reconstr Surg 1995;95:1275-1279.

19. Holtje WJ. Successful replantation of an amputated upper lip. Plast Reconstr Surg 1984;73:664-670.
20. Mortenson BW, Dawson KH, Murakami C. Medicinal leeches used to salvage a traumatic nasal flap. Br J Oral Maxillofac Surg 1998;36:462-464.

21. Pantuck AJ, Lobis MR, Ciocca R, Weiss RE. Penile replantation using the leech Hirudo medicinalis. Urology 1996;48:953-956.

22. de Chalain TM. Exploring the use of the medicinal leech: A clinical risk-benefit analysis. J Reconstr Microsurg 1996;12:165-172.

23. Foucher G, Henderson H, Maneau M. Distal digital replantation: One of the best indications for microsurgery. Int $\mathrm{J}$ Microsurg 1981;3:263-270.

24. Tamai S. Twenty years' experience of limb replantation-Review of 293 upper extremity replants. J Hand Surg Am 1982;7:549-556.

25. Hallock GG, Rice DC. Efficacy of venous supercharging of the deep inferior epigastric perforator flap in a rat model. Plast Reconstr Surg 2005;116:551-555; discussion 556.

26. Chang H, Minn KW, Imanishi N, Minabe T, Nakajima H. Effect of venous superdrainage on a four-territory skin flap survival in rats. Plast Reconstr Surg 2007;119:2046-2051.

27. Enajat M, Rozen WM, Whitaker IS, Smit JM, Acosta R. A single center comparison of one versus two venous anastomoses in 564 consecutive DIEP flaps: Investigating the effect on venous congestion and flap survival. Microsurgery 2010;30:185-191.

28. Dabb RW, Malone JM, Leverett LC. The use of medicinal leeches in the salvage of flaps with venous congestion. Ann Plast Surg 1992;29:250-256.

29. Wells MD, Manktelow RT, Boyd JB, Bowen V. The medical leech: An old treatment revisited. Microsurgery 1993;14:183-186.

30. Nakajima T. How soon do venous drainage channels develop at the periphery of a free flap? A study in rats. $\mathrm{Br} \mathrm{J}$ Plast Surg 1978;31:300-308.

31. Carter KC. Leechcraft in nineteenth century British medicine. J R Soc Med 2001;94:38-42.

32. Stainsby D, Russell J, Cohen H, Lilleyman J. Reducing adverse events in blood transfusion. Br J Haematol 2005;131:8-12.

33. Gauvin F, Lacroix J, Robillard P, Lapointe H, Hume H. Acute transfusion reactions in the pediatric intensive care unit. Transfusion 2006;46:1899-1908.

34. Chepeha DB, Nussenbaum B, Bradford CR, Teknos TN. Leech therapy for patients with surgically unsalvageable venous obstruction after revascularized free tissue transfer. Arch Otolaryngol Head Neck Surg 2002;128:960-965.

35. Haycox CL, Odland PB, Coltrera MD, Raugi GJ. Indications and complications of medicinal leech therapy. J Am Acad Dermatol 1995;33:1053-1055.

36. Whitaker IS, Izadi D, Oliver DW, Monteath G, Butler PE. Hirudo medicinalis and the plastic surgeon. Br J Plast Surg 2004;57:348-353.

37. Furnas HJ, Lineaweaver W, Buncke HJ. Blood loss associated with anticoagulation in patients with replanted digits. J Hand Surg Am 1992;17:226-229.

38. Dickson WA, Boothman P, Hare K. An unusual source of hospital wound infection. Br Med J (Clin Res Ed) 1984;289:1727-1728.

39. Whitlock MR, O'Hare PM, Sanders R, Morrow NC. The medicinal leech and its use in plastic surgery: A possible cause for infection. Br J Plast Surg 1983;36:240-244.

40. Bauters TG, Buyle FM, Verschraegen G, Vermis K, Vogelaers D, Claeys G, Robays H. Infection risk related to the use of medicinal leeches. Pharm World Sci 2007;29:122-125.

41. Lineaweaver WC, Hill MK, Buncke GM, Follansbee S, Buncke HJ, Wong RK, Manders EK, Grotting JC, Anthony J, Mathes SJ. Aeromonas hydrophila infections following use of medicinal leeches in replantation and flap surgery. Ann Plast Surg 1992;29:238-244.

42. Sawyer R. Leech Biology and Behaviour. Vol. II, Feeding Biology, Ecology, and Systematics. Oxford Science Publications, Clarendon Press Oxford. 1986.

43. Hermansdorfer J, Lineaweaver W, Follansbee S, Valauri FA, Buncke HJ. Antibiotic sensitivities of Aeromonas hydrophila cultured from medicinal leeches. Br J Plast Surg 1988;41:649-651.

44. Fenollar F, Fournier PE, Legre R. Unusual case of Aeromonas sobria cellulitis associated with the use of leeches. Eur J Clin Microbiol Infect Dis 1999;18:72-73.

45. Evans J, Lunnis PJ, Gaunt PN, Hanley DJ. A case of septicaemia due to Aeromonas hydrophila. Br J Plast Surg 1990;43:371-372. 
46. Lowen RM, Rodgers CM, Ketch LL, Phelps DB. Aeromonas hydrophila infection complicating digital replantation and revascularization. J Hand Surg Am 1989;14:714-718.

47. Lineaweaver WC, Furnas H, Follansbee S, Buncke GH, Whitney TM, Canales F, Bruneteau R, Buncke HJ. Postprandial Aeromonas hydrophila cultures and antibiotic levels of enteric aspirates from medicinal leeches applied to patients receiving antibiotics. Ann Plast Surg 1992;29:245-249.
48. Jacobs L, Chenia HY. Characterization of integrons and tetracycline resistance determinants in Aeromonas spp. isolated from South African aquaculture systems. Int J Food Microbiol 2007;114:295-306.

49. Braga A, Lineaweaver WC, Whitney TM, Follansbee S, Buncke HJ. Sensitivities of Aeromonas hydrophila cultured from medicinal leeches to oral antibiotics. J Reconstr Microsurg 1990;6:135-137.

50. Giele H, Cassell O. Plastic and Reconstructive Surgery. Oxford: Oxford University Press; 2008. 